\title{
Wilhelm Vallentin en Argentina [1904-1905]: proyectos de colonización entre actores locales y una trayectoria global
}

Resumen: Se presentan nuevos materiales sobre la vida del explorador alemán Wilhelm Vallentin con el objeto de conocer su itinerario, encuentros y proyectos en Argentina. Por medio de sus propios relatos de viaje, de la prensa periódica de habla alemana editada en Buenos Aires y de diverso material de archivo se ilustra la densa red social que la colectividad germanoparlante desplegó en ese país desde fines del siglo XIX. A través de esta trayectoria singular se espera mostrar el potencial de la escritura biográfica como medio para comprender una coyuntura específica de la historia global en sus articulaciones regionales y locales.

Palabras clave: biografía global, historia regional, historia global, inmigración.

\section{Wilhelm Vallentin in Argentina [1904-1905]: colonization projects between local actors and a global trajectory}

Abstract: This article presents new materials on the life of the German explorer Wilhelm Vallentin that reveal his itineraries, encounters and projects in Argentina. Using the explorer's own travel journals, the German periodical press published in Buenos Aires and various archive materials the article illustrates the dense social network that the German-speaking community had developed in Argentina since the late 19th century. Based on the detailed analysis of a single trajectory, this article shows the potential of biographical writing as a way to understand a specific juncture of global history in its regional and local articulations.

Keywords: global biography, regional history, global history, immigration.

\section{Wilhelm Vallentin na Argentina [1904-1905]: projetos de colonização entre atores locais e uma trajetória global}

Resumo: Apresentam-se novos materiais sobrea vida do explorador alemão Wilhelm Vallentin com o objetivo de conhecer seu itinerário, encontros e projetos na Argentina. Através dos seus relatos de viagem, da imprensa periódica de língua alemã editada em Buenos Aires e de diversos materiais de arquivo, ilustra-se a densa rede social que a comunidade germanófona implementou nesse país, desde o final do século XIX. Por meio dessa trajetória singular, espera-se mostrar o potencial da escrita biográfica como recurso para compreender uma conjuntura especificada história global, em suas articulações regionais e locais.

Palavras-chave: biografia global, história regional, história global, imigração.

Cómo citar este artículo: Gastón Alejandro Olivera, "Wilhelm Vallentin en Argentina [1904-1905]: proyectos de colonización entre actores locales y una trayectoria global”, Trashumante. Revista Americana de Historia Social 16 [2020]: 192-215.

DOI: 10.17533/udea.trahs.n16a10

Fecha de recepción: 8 de septiembre de 2019

Fecha de aprobación: 23 de abril de 2020

Gastón Alejandro Olivera: Estudiante de doctorado en Historia de la Universidad Nacional de San Martín.

Docente de la Universidad Nacional de la Patagonia.

Correo electrónico: kindgaston@gmail.com 


\section{Wilhelm Vallentin en Argentina [1904-1905]: proyectos de colonización entre actores locales y una trayectoria global}

Gastón Alejandro Olivera

"Curiosa figura la de este romántico trotamundos".

Armando Braun Menéndez, "El aporte alemán al progreso de la Patagonia”, Revista

Argentina Austral 33.348 (1961): 10.

\section{Introducción}

W ilhelm Vallentin, nacido el 7 de enero de 1862 en Preußisch Friedland al este de Prusia, fue un militar, funcionario estatal, escritor y periodista de intensa actividad a fines de siglo XIX. Pese a la densidad de su experiencia histórica y a la relativa notoriedad que alcanzó en su época, este explorador alemán ha sido prácticamente desatendido por la historiografia y los estudios sobre viajeros. Tras habernos ocupado de su vida y obra, consideraremos su breve estancia en Argentina y reconstruiremos detalladamente su itinerario a fin de prestar atención en sus prácticas y contactos con las redes sociales del país, cuestiones que hasta el momento solo habíamos esbozado en trabajos anteriores. ${ }^{1}$

Analizar detenidamente esa estadía es relevante en varios sentidos. En primer lugar, permite observar en primera persona procesos históricos considerados habitualmente de manera holística, es decir, sin la debida atención a las agencias y sus configuraciones sobre el terreno. Son ejemplos de dichos procesos la definición "metropolitana" de áreas de influencia geopolíticas, las modalidades concretas que asumió la presencia de agentes estatales en los territorios nacionales del sur argentino

1. Este artículo continúa la labor iniciada en Gastón Olivera, Del desamparo al imperio. Wilhelm Vallentin y el proyecto de colonización del Chubut bajo el signo del Kaiserreich, 1890-1914 (Buenos Aires: Prometeo Libros, 2015), trabajo ampliado posteriormente gracias a estadías de investigación en Argentina y Alemania, realizadas gracias al apoyo del Consejo Nacional de Investigaciones Científicas y Técnicas (CONICET) y del Servicio Alemán de Intercambio Académico (DAAD). 
al momento de su incorporación al mercado mundial, o a la propia presencia de este viajero en la región, considerada en ocasiones sencillamente como la hipóstasis del imperialismo alemán en la Patagonia. ${ }^{2}$

Es importante, en segundo lugar, porque Argentina, en general, y la Patagonia, en particular, fueron en esta etapa de su "trayectoria global" el objeto central de su intervención política e intelectual. ${ }^{3}$ Por tanto, una mirada atenta a sus actividades en ese país permite comprender los contextos locales (argentino, pero también "territoriano") en que se situó el intento por parte de Vallentin de fundar una colonia con población "germana" en el territorio del Chubut, en la Patagonia argentina, e indagar por las razones de tal decisión, así como por la perspectiva general que la nutría.

La reconstrucción detallada de sus encuentros y proyectos se realiza, en lo fundamental, a partir de la consulta de sus propios relatos de viaje, de la pesquisa en la prensa periódica editada en Argentina, así como de ciertas fuentes obtenidas en fondos de archivos nacionales y locales. Este material permite conocer sobre los motivos de su viaje a la Argentina, cómo fue su tránsito por este país y qué relaciones se establecieron entre este visitante y distintos sectores de la comunidad de habla alemana. Asimismo, permite saber cuáles fueron sus puntos de coincidencia, cuáles sus diferencias y si estableció también contactos con otros sectores locales; así como las circunstancias que facilitaron u obstaculizaron sus planes, además de resolver otros interrogantes.

La presencia de germanoparlantes en lo que vino a ser, luego de un complejo proceso histórico, el territorio de la República Argentina se remonta en el tiempo y el espacio hasta tiempos coloniales, pero fue a partir del último cuarto del siglo XIX que una comunidad en sentido estricto comenzó a formarse. Tuvo su origen en la llegada, en sucesivas oleadas, de nuevos inmigrantes movilizados tanto por los procesos de modernización de sus respectivos países como por las atrayentes perspectivas de la Argentina posterior a la "Conquista del desierto". Estos nuevos contingentes de mujeres y hombres condujeron a la diversificación de la colonia alemana del Plata, cuya composición social se modificó notoriamente, lo que generó la definición de identidades con un fuerte desarrollo asociativo y provocó el surgimiento de tensiones debido a situaciones tanto europeas como originadas en la dinámica de formación de una sociedad plural. El boom económico y comercial de la Argentina finisecular coincidió con la política expansiva del Imperio alemán y con el interés de las pujantes casas comerciales e industriales alemanas por tener

2. Sobre las implicancias teórico-metodológicas (y políticas) del término 'agency' o 'agencia histórica', véase Chris Barker, The SAGE Dictionary of Cultural Studies (London: SAGE Publications, 2004) 4.

3. Tomamos el concepto de Bernd Hausberger, ed., Globale Lebensläufe. Menschen als Akteure des weltgeschichtlichen Geschehen (Wien: Mandelbaum-Verlag, 2006). Otras reflexiones sobre las "biografias globales" pueden hallarse en Anaclet Pons, "De los detalles al todo: historia cultural y biografias globales", História da Historiografia 12 (2013): 156-175; Sebastian Conrad, Historia global. Una nueva visión para el mundo actual (Barcelona: Crítica, 2017). 
presencia en dicho país. En ese contexto, los "alemanes en el extranjero" —un concepto de reciente creación - llegaron a tener una nueva relevancia al reconocerse su potencial económico, de forma tal que comenzaron a hacerse esfuerzos oficiales y particulares para que estos sostuvieran un estrecho vínculo con Alemania en los campos de la técnica, la economía o la cultura, iniciativas de las que la colonia del Plata no estuvo ajena. El propio Estado argentino en proceso de modernización propició un vínculo más estrecho con su par alemán en el ámbito político, económico y militar, por ejemplo, valiéndose de profesionales o técnicos de varias ramas de actividad y fomentó el desarrollo de emprendimientos económicos con población de ese origen, bajo la premisa de que "el espíritu vivificante de la civilización europea" - tal como gustaba al Juan Bautista Alberdi de las Bases (1852) — solo llegaría a suelo argentino por medio de la inmigración. ${ }^{4}$

Para la primera década del nuevo siglo los alemanes constituían una parte importante de la joven nación y, pese a ser una colectividad menos numerosa que otras, su predicamento y su presencia en la vida política argentina era considerable. Sostenemos que Vallentin se sirvió de la agenda política y de colonización que promovían ciertos miembros de su élite para, poco después, tomar distancia de ella; mientras que estos vieron en él la posibilidad de expandir definitivamente sus objetivos ligados al fomento de la colonización. A través de esta trayectoria singular, por tanto, esperamos ilustrar la forma en que una coyuntura específica de la historia global puede ser vislumbrada en sus articulaciones regionales y locales, cuestión que en el caso de la Patagonia ha sido menos explorada desde la perspectiva de los actores germanoparlantes.

\section{Misión sudamericana y arribo a la Argentina [1903-1904]}

La primera parte de la vida de Wilhelm Vallentin puede subdividirse en cuatro momentos fundamentales: el primero, de instrucción militar y desempeño como sargento mayor de artillería en distintas dependencias del ejército alemán (aproximadamente entre 1878 y 1888); el segundo, de formación académica y dedicación a trabajos científicos, finaliza con su graduación como doctor en ciencias del Estado (Staatswissenschaften) (1891) y con la publicación de su disertación -y primer libro- (1893); el tercero, de incorporación al Ministerio de Relaciones Exteriores del Imperio para realizar el "servicio colonial” en el Camerún alemán (1892), donde tras un año y medio de actividad fue sancionado y cesado en su cargo, razón por la cual se le prohibió el ingreso a Alemania durante dos años; por último, de tránsito por distintas posesiones de Asia y el Pacífico en calidad de administrativo

4. Sobre las circunstancias en la Argentina de la época y la situación, dentro de ella, de la comunidad de habla alemana, véase Wilhelm Lütge y otros, Los alemanes en la Argentina. 500 años de historia (Buenos Aires: Editorial Biblos, 2017); Anne Saint Sauveur-Henn, Un siècle d'emigration allemande vers l'argentine 1853-1945 (Colonia: Böhlau, 1995); Benjamin Bryce, Ser de Buenos Aires. Alemanes, argentinos y el surgimiento de una sociedad plural 1880-1930 (Buenos Aires: Editorial Biblos, 2019). 
de sociedades coloniales (1894), tras lo cual regresó a África y se dirigió a Transvaal donde se involucró activamente en la guerra anglo-bóer como capitán en la artillería bóer (1895-1902). Con la caída de Pretoria se convirtió en prisionero de guerra y se le impidió regresar a la ahora nueva colonia británica por lo que debió retornar a Alemania junto a otros deportados.

Este tránsito durante una década por distintas posesiones europeas en Asia y África lo transformó de funcionario colonial en un "agente imperial" que, en los márgenes del servicio oficial, hacía política empuñando las armas y la pluma al calor de la disputa estratégica mundial. A modo ilustrativo: en el corto plazo que va de 1898 a 1903 publicó diez libros sobre estos asuntos de actualidad (dos de ellos en varios volúmenes). Esta vertiginosa producción coincidió con $-\mathrm{o}$, quizás, formó parte de - una campaña internacional de agitación que se desarrolló en los principales foros europeos, pero que se desplegó con particular ahínco en asociaciones y periódicos alemanes deseosos de conseguir un mayor compromiso de su gobierno con la causa bóer.

A la reputación conseguida en círculos académicos Vallentin sumó, ya entonces, el vínculo con sociedades comerciales o de colonización y con sectores que sostenían una abierta crítica del perfil que venía asumiendo el joven colonialismo alemán del que demandaban una renovación de su línea política, fuera para suavizarla (liberales) o para radicalizarla (pangermanistas). Los periódicos de mayor tirada del Imperio, como el Berliner Tageblatt, comenzaron a fijarse en su prolífera producción y lo reconocían como un experto en materia colonial, de forma tal que, en 1900 con apenas ocho años de iniciada su labor, la revista Deutsche Rundschau für Geographie und Statistik le dedicó una semblanza biográfica en la sección "Famosos geógrafos, naturalistas y viajeros". 5

En abril de 1903 Vallentin emprendió un viaje de exploración y estudio por Suramérica en representación de la Asociación Central de Geografia Comercial y Fomento de los Intereses Alemanes en el Extranjero (ZVfHG, por sus siglas en alemán) con asiento en Berlín, dirigida por el famoso geógrafo Robert Jannasch. ${ }^{6}$ El eje de su misión sería, según el testimonio recogido por el periódico Argentinisches Tageblatt, evaluar las posibilidades de un "mejor aprovechamiento de nuestro excedente poblacional emigrante que, por ejemplo, en Norteamérica es absorbido demasiado pronto, convirtiéndolo en nuestro competidor", una problemática que estaba en la agenda de aquella asociación con fuerte presencia política. Además, debía recorrer Brasil, los "Estados del Río de la Plata" (Argentina, Uruguay y

5. Los nombres de periódicos y revistas serán consignados en alemán. Los títulos de libros o artículos y el nombre de las instituciones, en cambio, figurarán en castellano en el cuerpo del texto y en su forma original a pie de página. Todas las traducciones corren por cuenta del autor y son acompañadas de la respectiva aclaración. Para la semblanza véase Friedrich Umlauf, ed., "Berühmte Geographen, Naturforscher und Reisende", Deutsche Rundschau für Geographie und Statistik (Wien-Pest-Leipzig) 1900: 571.

6. El nombre original en alemán del cual proceden las siglas es Zentralverein für Handelsgeographie und Förderung deutscher Interressen im Auslande. 
Paraguay), Perú, Chile y, junto con ello, estimar las perspectivas de "expansión del mercado para productos industriales alemanes por medio del direccionamiento de la corriente emigratoria hacia países de América del Sur". Una vez efectuado el recorrido debía "redactar vívidas narraciones, en especial, una ágil presentación de las condiciones económicas de aquellos países en la que también encuentre consideración la descripción de gentes y costumbres, así como del estado interno de aquellas repúblicas".?

Una vez llegado a Brasil recorrió los distintos territorios siguiendo la línea de la costa y dedicó buen tiempo a conocer su interior y no solo las ciudades más importantes. En especial, recorrió en detalle los estados del sur, Sao Paulo, Paraná, Santa Catharina, Rio Grande do Sul, donde existía una fuerte presencia de migrantes de habla alemana.

Arribó a la Argentina en la más completa reserva, en parte debido a que no lo hizo por el puerto de Buenos Aires como a menudo hacían otras personalidades del momento. Cruzó el río Uruguay desde la ciudad de Uruguayana, situada en el extremo oeste del estado de Río Grande do Sul, e ingresó por primera vez al país a través de Paso de los Libres, aproximadamente, en diciembre de 1903. Desde allí continuó por tierra hasta la ciudad de Corrientes, pero no permaneció en territorio argentino, sino que se dirigió directamente hacia Paraguay, tramo que realizó en barco sobre el río homónimo. Solo después de dedicar algunos meses al "país de los guaranís", el cual recorrió intensamente de norte a sur y desde el Alto Paraná en su parte oriental hasta el Gran Chaco en su parte occidental, volverá a Argentina atravesando el territorio nacional de Misiones.

Llegó a Buenos Aires a fines de marzo de 1904 y se alojó en el distinguido Royal Hotel ubicado en la intersección de las calles Corrientes y Esmeralda, punto de condensación de la vida cultural, social y política porteña. ${ }^{8}$ Esta "casa alemana de primera calidad" — tal como anunciaba su publicidad — se encontraba a pocos metros de los talleres del periódico Argentinisches Tageblatt, quizás el diario de habla alemana más prestigioso de Suramérica, propiedad de los hermanos Moritz y Theodor Alemann, quienes, además, eran sus directores y redactores en jefe. ${ }^{9} \mathrm{Va}-$ llentin visitó la redacción por propia iniciativa el 29 de marzo y el diario presentó al hasta entonces desconocido visitante con manifiesta curiosidad, lo identificó como doctor Hauptmann (capitán) y reportero-viajero que recorría el continente hacía casi un año en misión encargada por el periódico Berliner Tageblatt.

7. Las citas del párrafo corresponden a Argentinisches Tageblatt (Buenos Aires) 7 de abril de 1904: 1. Traducción del autor.

8. Se trataba de un complejo edificio de estilo fin de siècle adquirido en 1895 por el empresario hotelero Ludovico Schäfer.Véase una descripción en Caras y Caretas (Buenos Aires) 30 de mayo de 1903: 69.

9. Katrin Hoffmann, “¿Construyendo una 'comunidad”? Theodor Alemann y Hermann Tjarks como voceros de la prensa germanoparlante en Buenos Aires, 1914-1918", Iberoamericana 9.33 (2009): 121-137. Conviene agregar que Schäfer era un antiguo amigo de los hermanos Alemann. 
En general fue escasa la información que el diario pudo dar en un principio. Resulta curioso que debiera recurrir a notas de su par berlinés para obtener más datos respecto a su trayectoria, objetivos o planes, publicando recién el 7 de abril una amplia semblanza biográfica y un detalle de los propósitos de su viaje. Asimismo, reprodujo algunos de los artículos de su autoría aparecidos en Berliner Tageblatt a fin de que el público local conociera su estilo de escritura. ${ }^{10}$ Es evidente que Vallentin fue cauteloso al presentarse en el ambiente argentino, acaso consciente del eco que por entonces encontraba el “peligro alemán”, una campaña mediática presumiblemente promovida por agentes ingleses y norteamericanos. Es preciso apuntar, por lo demás, que la identidad de Vallentin como cronista se fue disolviendo conforme pasaron los meses para pasar a ser simplemente el representante de la ZVfHG.

\section{Tres viajes al interior de la República [abril a agosto de 1904]}

Al principio solo se supo que pretendía recorrer las antiguas colonias de la provincia de Santa Fe, una cita ineludible para quien quisiera informarse sobre el estado de las colonias de habla alemana en Argentina. No obstante, postergó esa excursión para privilegiar lugares menos frecuentes que le permitieran conocer al país de una manera más integral. Consagró los siguientes cinco meses a realizar tres viajes: el primero, a las provincias de Cuyo; el segundo, hacia el sur de la provincia de Buenos Aires y La Pampa central; y el tercero, en dirección al norte y noroeste.

El 20 de abril de 1904 se dirigió al primero de esos destinos. Tenía previsto permanecer un mes recorriendo los puntos más importantes de esas provincias para regresar a tiempo a la capital a fin de presenciar los festejos del 25 de mayo. Un informante del Argentinisches Tageblatt en San Juan dio cuenta de su llegada a esa ciudad el 1 de mayo. Mencionaba — por primera vez desde que su arribo tomó estado público - que viajaba en representación de una "asociación geográfica" y que recorrió las bodegas y fábricas más importantes, el dique y el sistema de irrigación. Fue recibido en prolongada audiencia por el ministro de agricultura Aubone y por el gobernador Enrique Godoy, un militar que había participado en la guerra del Paraguay, en la "Conquista del desierto" en Patagonia y que en octubre de ese año se convertiría en el nuevo ministro de Guerra y Marina. ${ }^{11}$

El 6 de mayo se encontraba en Mendoza desde donde envió una postal a Theodor Alemann en la que confirmaba haber sido recibido de la mejor manera por Hans von Toll, quien fuera "una personalidad industrial, intelectual y científica de nota” según el juicio del Álbum del Centenario publicado años más tarde con

10. Sin embargo, y esto es algo que probablemente no recordarían los propios editores, Vallentin ya había aparecido en sus páginas hacía algunos años. Un artículo publicado sobre el final de la guerra anglo-bóer hacía eco de sus denuncias sobre la brutalidad inglesa contra mujeres y niñas en manifiesto incumplimiento de la Convención de Ginebra.Véase "Englische Bestialität gegen Burenfrauen und Mädchen”, Argentinisches Wochenblatt (Buenos Aires) 9 de abril de 1902: 17.

11. Argentinisches Tageblatt (Buenos Aires) 7 de mayo de 1904: 1. Traducción del autor. 
motivo de los festejos patrios. En esta provincia visitó también San Rafael desde donde remitió a Alemann una carta resumiendo las primeras impresiones de su viaje por Cuyo:

Ya he visto Mendoza, San Rafael y San Juan y estoy sorprendido por lo que he encontrado allí; se han hecho grandes logros en ambas provincias, no solo en cuanto a la viticultura y la producción de vino sino también en lo que respecta a las restantes áreas económicas —entre otras cosas, principalmente el sistema de regadío- [...] En general no puedo más que manifestarme elogiosamente sobre todo, y lo único que lamento es que todo esto sea tan poco conocido en casa. ${ }^{12}$

El 14 de mayo se dirigió a través del Ferrocarril Gran Oeste Argentino desde Mendoza a la provincia de San Luis, donde conoció su capital y las ciudades de La Cumbre y Villa Mercedes. Allí empalmó con el Ferrocarril de Buenos Aires al Pacífico y atravesó el sur de Córdoba para llegar a Rufino en el suroeste de la provincia de Santa Fe, sitio de numerosas colonias de habla alemana. El 18 de mayo se encontraba de regreso en Buenos Aires satisfecho por la amable acogida que le dispensara "la colonia alemana" en las provincias de Cuyo y después de haber recogido suficiente material para sus informes y obra en preparación.

Sus estudios interesaron al prestigioso Hugo Stroeder, quien invitó al viajero en más de una oportunidad a conocer sus emprendimientos. ${ }^{13}$ En efecto,Vallentin fue parte de la comitiva que acompañó a este emprendedor a Chacabuco — distante 200 km de Capital Federal - el 29 de mayo para inspeccionar las tierras recientemente adquiridas por su empresa con destino a la futura colonia "La Carolina". Stroeder organizó, además, un viaje de reconocimiento por las colonias fundadas en el sur de esa provincia y en el territorio de La Pampa, con lo cual amplió la invitación a Moritz Alemann, quien no recorría esta región desde el año 1898.

De esta forma, Vallentin emprendió su segundo viaje de importancia. Partió el 3 de junio desde Buenos Aires en compañía de Jorge Keller, miembro de Colonización Stroeder y al mismo tiempo emprendedor particular de colonias. Alemann y Stroeder una semana más tarde (11 de junio) viajaron en el Ferrocarril Oeste a través de Pehuajó y Trenque Lauquen para sumarse a la comitiva en "el asentamiento germano" de Salliqueló. Pese a los inconvenientes hallados y a la severidad del clima, recorrieron en carro, a caballo y en tren esas extensas regiones, estudiando exhaustivamente estancias y colonias, mientras entraban en contacto con pobladores, comerciantes e industriales y participaban de su vida social antes

12. Argentinisches Tageblatt (Buenos Aires) 15 de mayo de 1904: 1. Traducción del autor.

13. Stroeder había llegado al país proveniente de Alemania en 1881 y estableció buenos vínculos con Bernardo de Irigoyen, a la postre gobernador de la provincia de Buenos Aires por la Unión Cívica Radical. Este le encargó en 1899 que implementara un sistema de colonización y fundación de asentamientos agrícola-ganaderos, lo que dio lugar a la fundación de la empresa de colonización Stroeder y Cía. que tuvo importancia posteriormente al fundar asentamientos poblacionales en La Pampa, Santa Fe, Córdoba y el sur bonaerense, entre ellos el mismo pueblo de Stroeder. 
de regresar a Buenos Aires en los primeros días julio, tras un mes de agotador recorrido. $^{14}$

El tercer viaje en esta etapa de su estadía comenzó el 19 de julio y lo condujo hacia el norte y noroeste, a las provincias de Santa Fe, Córdoba y Tucumán. Recorrió Rosario, Juárez Celman, Isla Verde, Cañada de Gómez, Carcarañá, San Gerónimo y Roldán a fin de "estudiar los logros de la diligente cultura germana”. Luego siguió su viaje a las poblaciones de Santa Fe, Frank, Esperanza y San Carlos "para conocer la historia de las colonias más antiguas de Argentina". Más tarde se dirigió hacia Tucumán, "para endulzar sus impresiones de viaje” y hacia Córdoba y "la magnífica Sierra, para descubrir también la belleza paisajística de Argentina". ${ }^{15}$ De este tramo solo contamos con noticias de su actividad en Cañada de Gómez, cuando cerca del 28 de julio fue acogido por un colaborador permanente del Argentinisches Tageblatt, que firmaba sus artículos de opinión como "E. M.”. Juntos realizaron varios paseos en los alrededores, visitaron establecimientos industriales e hicieron un tour por la colonia y por la zona de chacras. El anfitrión declaró luego que en Vallentin reconocieron a "un escritor de gran cultura, que ha viajado mucho" y "que las horas que pasamos en tan buena compañía con conversaciones interesantes serán siempre un agradable recuerdo". ${ }^{16}$

En un principio había proyectado conocer también las poblaciones de Berna, Malabrigo, Calchaquí y llegar hasta el Chaco para conocer las industrias del quebracho y visitar a Alwin Matschnig. El panorama de los promotores germanoparlantes de la colonización en el territorio argentino estaría incompleto sin este emprendedor de la industria algodonera, residente en la colonia Romang, pero con influencia en una amplia zona del noreste santafesino incluido Paraguay. Era un antiguo amigo de la familia Alemann y, por aquel entonces, uno de los más importantes columnistas del diario. ${ }^{17}$ Sin embargo, el encuentro no se concretó pese al interés que había manifestado Matschnig: "[s]i el conocido explorador señor Dr. Vallentin desea deleitar [al pueblo de] Romang con su visita, será recibido con todos los debidos honores". Cuando, más tarde, Vallentin aluda a este tercer trayecto

14. Dos fotografias publicadas en un libro de Moritz Alemann ilustran esta cumbre de emprendedores. En ellas Vallentin, Stroeder, Alemann y Keller son retratados en distintas "situaciones de campo" al tiempo que una flameante bandera del "Emporio Colonización Stroeder" corona una de las escenas. La inclusión de estas imágenes en una publicación que vio la luz poco después del paso de Vallentin por el país no parece anodina. Probablemente expresa la forma en que los actores locales "exhibieron" el contacto con este viajero y promotor para darle mayor alcance a sus propias iniciativas.Véase Moritz Alemann, Am Rio Negro. Ein Zukunftsgebiet germanischer Niederlassung: drei Reisen nach dem argentinischen Rio Negro-Territorium (Berlin: Dietrich Reimer, 1907) 32.

15. Argentinisches Tageblatt (Buenos Aires) 19 de julio de 1904: 1. Traducción del autor.

16. Argentinisches Tageblatt (Buenos Aires) 30 de julio de 1904: 1. Traducción del autor.

17. En 1899 había escrito junto a Johann Alemann, padre de Theodor y Moritz, el libro Marcos Bustamante. De la vida de un gaucho. Una narración fiel a la verdad, publicada en Buenos Aires por la editorial Helvetia. 
no mencionará el Chaco y, además, es extraño que tampoco existan noticias en los diarios sobre su paso por esa región. ${ }^{18}$

\section{Conferencia del Turnverein: balance y llamado a la acción [agosto de 1904]}

Stroeder, Keller y Moritz Alemann estaban aglutinados en la Asociación Protectora de los Inmigrantes Germánicos ( $\mathrm{VzSgE}$, por sus siglas en alemán) fundada en 1882 por Ernst Bachmann en cooperación con otros miembros de la colonia como Hermann Tjarks — propietario del diario Deutsche La Plata Zeitung-, el librero y editor Ernest Nolte, el arquitecto Carlos Altgelt, los comerciantes Teodoro Hegenbarth y Gustav Mayer, el banquero Ernesto Tornquist, entre otros. ${ }^{19}$

En el año 1904 esta asociación, cuyo propósito era "apoyar a los inmigrantes germanos con concejos e información”, estaba presidida por Stroeder y fungía como secretario Moritz Alemann. A mediados de abril su directorio invitó a Vallentin a dictar una conferencia para reunir fondos en beneficio de la asociación. Los organizadores consideraban que este "conocedor del mundo" podía, como pocos, ofrecer una mirada comparativa sobre la situación de Argentina desde una perspectiva global y con relación a otros lugares del continente; un balance de sumo interés para la colonia local a cuyos miembros — "incluidas las mujeres"convocaron desde las páginas de los diarios. Se esperaba que en su alocución expusiera "sus puntos de vista sobre Argentina, en lo concerniente a medidas de cualquier tipo para el fomento y la derivación de la inmigración germánica, para la inversión de capitales y para una organización sistemática como ya ocurre en otros países de colonización". ${ }^{20}$

El evento debió postergarse hasta su regreso del interior del país, y se celebró finalmente el 25 de agosto en el salón de la Sociedad Alemana de Gimnasia de Buenos Aires ante un auditorio colmado. Contó con la presencia de numerosas personalidades oficiales: el doctor Georg Goerrissen en representación del ministro de agricultura Wenceslao Escalante; los ministros plenipotenciarios del Imperio alemán (Freiherr von Waldthausen) y de Austria-Hungría, el cónsul general y los representantes diplomáticos de Suiza (Joseph Choffat), de los Países Bajos (L.Van Riet) y de Escandinavia. Si bien se esperaba la asistencia de Juan Alsina, director de la Dirección General de Inmigración, este se excusó por escrito. ${ }^{21}$

Tras una breve presentación a cargo de Stroeder,Vallentin disertó "con voz firme y sin interrupciones" por el plazo de una hora y media, bajo la atenta mirada del público. En una primera parte abordó la cuestión emigratoria como fenómeno global,

18. Carta de Matschnig fechada el 1 de agosto, aparecida en Argentinisches Tageblatt (Buenos Aires) 4 de agosto de 1904: 1. Traducción del autor.

19. El nombre original en alemán del cual proceden las siglas es Verein zum Schutze germanischer Einwanderer.

20. Argentinisches Tageblatt (Buenos Aires) 23 de agosto de 1904: 1. Traducción del autor.

21. Argentinisches Tageblatt (Buenos Aires) 26 de agosto de 1904: 1. 
en cuanto problema social de la historia reciente alemana, luego describió la situación de la colonia alemana en Brasil y Paraguay para finalizar con sus impresiones de la realidad argentina tras ocho meses de estadía. En su discurso apostó por una urgente combinación de Wirtschafts und Auswanderungspolitik (política económica y emigratoria), en la que refería la necesidad de fomentar la emigración "germana" a este país y delineaba algunas propuestas que tendieran a "la concreción de una colonización planificada". ${ }^{22}$

Este diagnóstico y su programa de acción en modo alguno eran novedosos para la élite de habla alemana local. Según la complaciente crónica del Argentinisches Tageblatt, sus declaraciones "en esencia constituyen un eco de lo que a menudo y casi hasta la exasperación se ha dicho y repetido en nuestro diario, por desgracia hasta la fecha sin un éxito visible en la práctica". Pese a ello, Theodor Alemann se mostró optimista:

Esperamos que la elocuencia del Dr. Vallentin quiera lograr despertar en muchos corazones alemanes un eco sobre la importancia de estos esfuerzos y encauzar un movimiento que, de una vez por todas, intente resolver el problema de la inducción de una más numerosa inmigración germánica sobre la base de la promoción recíproca, tanto aquí como allá. Esto solo es posible mediante la ayuda mutua entre todos, a través de la organización, de la sinergia del capital, del espíritu emprendedor y del trabajo; una inmigración no planificada a nosotros aquí no nos beneficia nada y menos aún a la vieja patria..$^{23}$

El texto de la conferencia fue publicado ese mismo año como separata del periódico Deutsche La Plata Zeitung bajo el título Kolonialpolitische Studien mit besonderer Berücksichtigung Argentiniens. ${ }^{24}$ En español, probablemente por encargo de los hermanos Alemann, se publicó como Estudios politico-coloniales refiriendose muy especialmente a la Republica Argentina [sic], con traducción a cargo del doctor Pablo Maertens, miembro de la mesa de redacción de Argentinisches Tageblatt desde hacía más de una década y él mismo autor de libros sobre temáticas afines.

\section{Encuentro con Robert Jannasch e inicio de la acción colonizadora [octubre de 1904 a enero de 1905]}

Resulta llamativo que Vallentin no considerara a la VzSgE como una institución adecuada para canalizar su iniciativa colonizadora y que, incluso en la conferencia organizada por esta, demandara la formación de una nueva entidad:

22. Argentinisches Tageblatt (Buenos Aires) 26 de agosto de 1904: 1. Traducción del autor.

23. Argentinisches Tageblatt (Buenos Aires) 26 de agosto de 1904: 1. Traducción del autor.

24. Wilhelm Vallentin, Kolonialpolitische Studien mit besonderer Berücksichtigung Argentiniens (Buenos Aires: Separatabdruck aus der Deutschen La Plata Zeitung und La Plata Post, 1904). 
Por ejemplo, jlógrese una asociación [Verein] que trabaje y actúe de acuerdo con las directivas señaladas! Lógrese una Sociedad [Gesellschaft], por mí una Sociedad Alemana - Argentina de Colonización —el nombre es menos importante, sobre la marcha llegará — una sociedad, semejante a la Hansa [en Brasil], similar a otras probadas empresas de colonización que [...] se han organizado firmemente y a continuación se dieron a la tarea de la colonización sistemática con germanos de grandes o pequeños territorios. ${ }^{25}$

La colonización como sistema suponía que una compañía semejante se ocupase de tres tareas fundamentales: "1. Adquisición de tierras. 2. Derivación e inversión de capitales alemanes. 3. Derivación, mejor dicho, desviación de la corriente de emigración germana". La VzSgE se hizo eco de esta demanda y reunida en asamblea general el 16 de septiembre de 1904 modificó su denominación de Asociación Protectora de los Inmigrantes Germánicos a la más amplia y proactiva Asociación para el Fomento de la Inmigración Germánica (VzFgE, por sus siglas en alemán), lo que supuso una actualización de sus principios de organización de cara a los vientos de época. ${ }^{26}$

La actividad de Vallentin en el país recibió un fuerte respaldo a fines de ese mes con el arribo desde Brasil de su antiguo amigo el doctor Robert Jannasch, presidente de la ZVfHG, en cuya representación — como vimos- recorría Suramérica. Llegaba a Buenos Aires el más destacado promotor de la emigración alemana, su teórico y práctico más representativo a nivel mundial, además de ser una figura importante en la política del Imperio. Desde el mes de abril desplegaba una intensa actividad propagandística en el sur de Brasil y la posibilidad de que ampliara su recorrido a la Argentina había sido deseada y demandada en los medios gráficos locales. Quizás la presencia simultánea de Vallentin, o su intermediación, ayudó para que finalmente decidiera visitar al vecino país.

Entretanto, este había avanzado en la dirección esbozada en su conferencia y el 22 de septiembre coordinó una primera reunión con representantes del comercio y el capital alemán en el salón del Royal Hotel, a la que también asistieron el ministro plenipotenciario alemán Von Waldthausen, el cónsul general Von Sanden así como el experto en asuntos comerciales el doctor Stoepel. El objeto del cónclave era transmitirles las ideas sostenidas en aquel discurso y solicitarles la puesta en marcha de tareas prácticas urgentes que tendieran al impulso de la inmigración alemana.

Esta reunión fue el punto de partida de una iniciativa conjunta que cristalizó el día 27 de septiembre con la fundación de la Sociedad Alemana para Emprendimientos

25. Vallentin, Kolonialpolitische 21. Traducción del autor. Destacado en el original.

26. Para la cita véase Vallentin, Kolonialpolitische 21. Traducción del autor. Destacado en el original. El nombre original pasó a ser Verein zur Förderung germanischer Einwanderung y una de las primeras acciones tras esta renovación fue la publicación de un guía de colonización que, si bien figuraba como una obra colectiva, fue redactada por Alwin Matschnig a pedido del directorio. Véase Alwin Matschnig, Argentinien als Ziel für germanische Auswanderung (Buenos Aires: H. Herpig, 1906). 
Económicos en Argentina (DGwUA, por sus siglas en alemán), ${ }^{27}$ en pos de la cual se formó un comité directivo provisorio. En esta segunda asamblea participaron, además de los anteriormente nombrados, el director local del Deutsche Bank; el profesor Rudolf Hauthal, naturalista del Museo de la Plata y por entonces presidente de la Sociedad Científica Alemana, y el recién llegado doctor Robert Jannasch, a quien Vallentin introdujo en la asamblea "con las sencillas pero sentidas palabras": he aquí a "mi maestro y amigo!". Jannasch se manifestó en todo de acuerdo con las aspiraciones y esfuerzos desplegados por Vallentin en el país y tomó a su cargo la representación en Europa de los intereses de la flamante asociación. ${ }^{28}$

Ambas personalidades tuvieron la oportunidad de presenciar la histórica transición de gobierno que llevó a Manuel Quintana a la presidencia el 12 de octubre de 1904. Merece ser destacado que cuatro días antes del traspaso de mando el presidente saliente, Julio A. Roca, y su ministro de agricultura, W. Escalante, firmaron un decreto que reservaba tierras en el territorio nacional del Chubut para la fundación de una colonia agrícola pastoril en la cuenca del río Pico. Este instrumento legal fue el antecedente que permitió a Vallentin, pocas semanas después (25 de octubre), elevar al nuevo gobierno argentino la propuesta de fundación de una "colonia germana" en las tierras de dicha reserva, proyecto que ya incluía un listado de eventuales colonos. ${ }^{29}$

Tras las actuaciones de forma de la División de Tierras y Colonias del Ministerio de Agricultura, el nuevo presidente reservó mediante un decreto el 29 de noviembre de 1904 y por el término de catorce meses "una superficie aproximada de noventa leguas cuadradas en la cuenca del Río Pico y sus afluentes limitada por el Lago General Paz, el 'Divortium Acuarium' continental y la línea limítrofe con la República de Chile, con destino a ser adjudicada en lotes de 2500 hectáreas cada uno" a los colonos indicados en la propuesta (artículo $1^{\circ}$ ). La obtención de esta reserva permitió a Vallentin dar un paso importantísimo para la consecución de su proyecto conforme a las ideas trazadas. Para entonces se contaba con un incipiente marco institucional, con experimentados apoyos locales e internacionales y con tierras para proyectar un ensayo colonizador con población "germana" que sirviera de señuelo para la intervención definitiva del capital alemán. Mientras Jannasch visitaba el interior (Córdoba, Rosario, Esperanza, Bahía Blanca), Vallentin continuó

27. El nombre original en alemán del cual proceden las siglas es Deutsche Gesellschaft für wirtschaftliche Unternehmungen in Argentinien.

28. Sobre la actividad científica de Hauthal véase Alberto C. Riccardi, "El Museo de La Plata en el avance del conocimiento geológico a fines del siglo XIX”, Serie Correlación Geológica 24 (2008): 109-126. Para las citas véase Argentinisches Tageblatt (Buenos Aires) 30 de septiembre de 1904: 1. Traducción del autor.

29. Que existiera una propuesta precedente por parte de Vallentin se desprende de la letra del decreto de 29 de noviembre de 1904 y de la carta que él le dirigiera desde Buenos Aires al ministro Damián M. Torino el 6 de julio de 1905. AHPCh, Rawson, Argentina, Fondo General, rollo n. 065, f. 1. En rigor, el decreto no deja claro si él solicitó específicamente esas tierras o si el gobierno le reservó en ese territorio en atención a sus intereses estratégicos. 
con los trámites para dar vida a la asociación, se entrevistó, por ejemplo, con el nuevo ministro de agricultura Damián M. Torino el 19 de octubre.

El retorno de Jannasch a Buenos Aires fue una ocasión propicia para que la Sociedad Científica Alemana, en la persona de su director Hauthal, lo invitara a brindar una conferencia. La disertación, titulada "Norteamérica y el canal de Panamá”, se pronunció el día 24 de octubre en la misma sala de la Turnverein que había acogido a Vallentin en agosto y fue presenciada por el ministro V. Waldthausen, el ministro consejero Graf Hacke y el cónsul general Von Sande. Al día siguiente Jannasch partió directamente hacia Alemania con la misión de robustecer la nueva sociedad.

Vallentin, en cambio, permaneció en el país realizando gestiones y nuevas excursiones como la que efectuó a la región del delta del Paraná en la primera quincena de noviembre de 1904, en la que coincidió con el capitán austríaco Mateo Gebhardt de la Gendarmería Volante, quien le asistió por encargo del gobierno. ${ }^{30}$ Mientras tanto, ajustaba los últimos detalles de su incursión a los territorios nacionales del sur prevista para finales de ese año. El propósito del viaje sería "explorar detenidamente la fértil zona del Río Pico que le fue cedida por el gobierno con propósitos de colonización", para examinarla y comprobar su capacidad de poblamiento. Utilizaría la ocasión para atravesar los Andes en dirección a Chile, tal como había previsto en un principio, y para efectuar una exploración integral de la amplia región cordillerana. ${ }^{31}$

\section{A caballo por la Patagonia [febrero a junio de 1905] ${ }^{32}$}

El anunciado viaje hacia los territorios nacionales del sur debió ser postergado a causa de la sublevación cívico-militar por medio de la cual la Unión Cívica Radical, encabezada por Hipólito Yrigoyen, intentó derrocar al gobierno de Quintana, pues se acusaba al Partido Autonomista Nacional de fraude y se pedían elecciones libres y democráticas. Esto afectó la preparación de su viaje en la medida en que había programado arribar a Bahía Blanca, unos de los focos de aquel levantamiento, para seguir desde allí hacia el sur. ${ }^{33}$

30. En julio de ese año Gebhard había sido comisionado por el gobierno de la provincia de Buenos Aires para "conseguir un poco orden" en aquella zona ribereña. Argentinisches Tageblatt (Buenos Aires) 22 de julio de 1904: 1. Traducción del autor. Su trayectoria represiva lo conduciría años más tarde a la Patagonia por haber sido designado como jefe de la Policía Fronteriza, creada el 1 de febrero de 1911 por el presidente Roque Sáenz Peña. Allí fueron habituales los vejámenes, torturas y muerte infringidos por ese cuerpo policial a los pobladores locales.

31. Argentinisches Tageblatt (Buenos Aires) 20 de febrero de 1905: 1; Argentinisches Tageblatt (Buenos Aires) 5 de mayo de 1905: 1; Argentinisches Tageblatt (Buenos Aires) 22 de julio de 1905: 1. Traducción del autor.

32. Para esta sección hemos utilizado, principalmente, Wilhelm Vallentin, Chubut: Im Sattel urch Kordillere und Pampa Mittel-Patagoniens (Argentinien) (Berlin: Hermann Paetel, 1906).

33. Durante su estadía en Suramérica presenciaría, directa o indirectamente, sublevaciones, golpes de Estado o guerras civiles en cada uno de los países que visitó: Brasil, Uruguay, Paraguay, 
Una vez llegado a Bahía Blanca aguardó la llegada de "su amigo de largos años" "Dr. med." conde Rudolf von Starhemberg de Viena, quien "lleno del mismo decidido afán, quiso unirse a la expedición como naturalista". ${ }^{34}$ Juntos partieron hacia Neuquén en el Ferrocarril del Sud cerca del 19 de febrero. Allí comenzó el recorrido a caballo por los puntos más importantes de Neuquén y Río Negro donde, según expresó Vallentin más tarde, fue recibido de la manera más amigable y atenta por parte de la población y de las autoridades. En efecto, exploró el sur de Neuquén por sugerencia e indicación personal del gobernador Carlos Bouquet Roldán acerca de quien decía: "me ha apoyado de la manera más amable con asesoramiento y asistencia”. En compañía de un baqueano "medio indígena” llamado González, recorrió la región entre el río Neuquén y el Limay, entre ellos Junín de los Andes y San Martín de los Andes, además de San Carlos de Bariloche. ${ }^{35}$

Desde el Nahuel Huapi se dirigió en barco, primero, y cabalgando, después, a "la zona alemana de Chile" para hacer una excursión hacia las poblaciones en torno al lago Llanquihue (Puerto Octay, Frutillar, Puerto Varas) y arribar luego a Puerto Montt. Tras su regreso al lado argentino continuó desde Bariloche hacia el sur por los puntos más destacados del oeste rionegrino. El 28 de marzo de 1905 Vallentin anunció telegráficamente a Buenos Aires su llegada a Norquinco, entonces perteneciente a Chubut, y adelantaba su entusiasta opinión respecto al brillante futuro que auguraba a la región. ${ }^{36}$ Destinó casi veinte días a estudiar el oeste chubutense, continuó a caballo a través delValle Nuevo, Cholila y colonia 16 de Octubre, hasta llegar finalmente al río Pico en la semana del 15 al 20 de abril.

Una vez inspeccionada la concesión emprendió su retorno a través de la colonia Sarmiento. Como excombatiente por la independencia bóer y prisionero de una guerra cuyas marcas seguían muy vivas en su pensamiento e identidad, el reencuentro con bóeres que habitaban allí debió ser una experiencia trascendente. ${ }^{37}$ Después de recorrer la zona de Rada Tilly y la colonia Escalante continuó a

Argentina y Chile. Quizás esta circunstancia explique su ingreso a Argentina directamente desde Brasil, eludiendo Uruguay donde en 1904 se había desatado una revolución y guerra civil. Este escenario político continental no afectó su optimismo, como sí ocurrió con otros voceros alemanes que vieron en esta inestabilidad un elemento que impactaba negativamente en las posibilidades de "progreso" de la región.

34. Argentinisches Tageblatt (Buenos Aires) 20 de febrero de 1905: 1. Traducción del autor. La historia de esta amistad, los motivos del viaje de este conde a Neuquén y su posible relación con la casa Starhemberg de la alta nobleza austríaca son aún desconocidos. Uno de los miembros más notables de esta familia fue el príncipe Ernst Rüdiger von Starhemberg (1899-1956), político y vicecanciller de Austria que en 1942 debió exiliarse en Argentina donde permaneció hasta 1955.

35. Wilhelm Vallentin, Ein Unerschlossenes Kulturland. Nëuquén und Rio Negro (Argentinien) (Berlin: Hermann Paetel, 1907) 65.

36. Argentinisches Tageblatt (Buenos Aires) 29 de marzo de 1905: 1. Traducción del autor.

37. Todavía se hacía llamar a sí mismo y firmaba cada escrito como "Dr. Kapitän”, además de aludir esporádicamente a sus vivencias en Sudáfrica. El 14 de julio de 1904 murió Paul Kruger, expresidente de la República Sudafricana independiente bóer y líder de la resistencia antibritánica. Theodor Alemann solicitó a Vallentin que escribiera una reminiscencia sobre su 
lo largo del río Chico en dirección a Camarones, donde sufrió las inclemencias de aquel invierno. Llegó al valle inferior del río Chubut en los últimos días del mes de mayo. El informante del Argentinisches Tageblatt en Trelew, quien firmaba "H." — acaso la abreviatura de Eduardo Hahn_-, estaba debidamente informado del "viaje de exploración y estudio económico-político" que Vallentin había emprendido a mediados de febrero y con seguridad habría aguardado su llegada. Por su conocimiento de la región y sus buenas vinculaciones - Hahn fue uno de los cinco miembros electos del primer Concejo Municipal de Trelew, creado en 1904- sirvió de intermediario con los miembros de la élite territoriana, entre ellos con el gobernador Julio Lezana a quien Vallentin visitó en Rawson. ${ }^{38}$

Es curioso que Y Drafod y La Cruz del Sur - los únicos medios gráficos del Chubut, editados en Trelew y Rawson respectivamente-, siempre bien informados de las noticias provenientes de Buenos Aires que implicaran a la región, en ningún momento dieran cuenta del decreto de reserva de tierras de noviembre de 1904 ni informaran sobre la presencia de Vallentin durante los dos meses que duró su estadía en el Territorio. En cambio, sí registraron su partida. El semanario de la colectividad galesa se limitó a ingresar su nombre en una lista más general de pasajeros que marchaban hacia Buenos Aires. Por su parte, el semanario salesiano anunció el 11 de junio de 1905 en un suelto titulado "Explorador" la partida en el vapor Camarones del "célebre é ilustrado explorador Doctor Valentin" [sic] hacia Buenos Aires. Esta referencia y la indicación de que una vez regresado a la capital conferenciaría con el padre Lino Delvalle Carbajal sugieren que Vallentin tuvo ocasión de conversar en Rawson con miembros de la congregación salesiana, probablemente con Bernardo Vacchina, jefe de la misión y fundador del semanario. Un parecer igualmente halagüeño sobre Vallentin expresó Ángel C. Fernández de Cabrero, corresponsal del diario La Prensa y reconocido comerciante y funcionario consular de España en Trelew. ${ }^{39}$

Otros importantes viajeros compartirían el mismo vapor: el propio gobernador Julio Lezana; Marcelino B. Martínez, inspector del Consejo Nacional de Educación; el ingeniero Lázaro R. Molinari y Adolfo Pigretti, encargados de la mensura en la colonia 16 de Octubre y en su ensanche; el teniente coronel Alfonzo Durand, llegado

antiguo compañero de armas en lo que fue su primera intervención como autor en las hojas del periódico. Wilhelm Vallentin, “Zum Tod des Präsidenten Krüger”, Argentinisches Tageblatt (Buenos Aires) 18 de mayo de 1904: 1-2.

38. A partir de julio de ese año Hahn reemplazaría a Federico Schmied como corresponsal del Argentinisches Tageblatt en el territorio del Chubut, quien venía desempeñando ese rol desde el año 1900. Schmied se hallaba radicado en el Territorio desde 1898 cuando era "un poderoso factor de nuestro progreso en diversos órdenes". El Pueblo (Trelew) 1 de enero de 1919: 50. De esta manera, llegó a ser miembro del Concejo Municipal de Rawson hasta que presentó su renuncia en septiembre de 1904. Y Drafod (Trelew) 11 de noviembre de 1904: 4.

39. Y Drafod (Trelew) 16 de junio de 1905: 1-4; Cruz del Sur (Rawson) 11 de junio de 1905: 95. Carbajal fue un sacerdote y especialista en ciencias naturales que recorrió extensamente la Patagonia desde finales de siglo XIX. Para la opinión de Cabrero véase Argentinisches Tageblatt (Buenos Aires) 7 de junio de 1905: 1. 
a Chubut para cumplir una misión administrativa militar, junto a su acompañante el señor Juan S. Dillon, venido para inspeccionar establecimientos y reconocer posibilidades de negocios; y Francisco Preston, administrador de la Compañía de Tierras Sud-Argentina de capitales ingleses. En suma, durante los seis días que demoró el Camarones en llegar al puerto de Buenos Aires, Vallentin tuvo la posibilidad de dialogar, coincidir o diferir con personas conocedoras de las condiciones y posibilidades de la región, que no solo posaban su mirada y expectativas en ella, sino que tenían intereses e injerencia directa en los destinos del Territorio. No podemos saber si efectivamente ocurrió así, pero es sugerente que al ingeniero Pigretti luego se le designara oficialmente para mensurar la recién fundada colonia alemana en la cordillera. ${ }^{40} \mathrm{Si}$ a ello sumamos sus anteriores encuentros $-\mathrm{y}$ los que tuvo y no dejaron rastros - es innegable que también en Chubut logró vincularse con los actores más representativos de la élite territoriana del momento, cuando esta desplazaba a la clase dominante galesa y su particular proyecto económicopolítico para la región. ${ }^{41}$

\section{Nuevas gestiones y retorno a Alemania [junio a agosto de 1905]}

Desde principios de ese año se sabía que, una vez que finalizara el viaje a la Patagonia, Vallentin regresaría a Alemania "donde ya lo aguardan otras difíciles tareas". ${ }^{42}$ Por ese motivo desarrolló una amplia actividad en Buenos Aires tendiente a fortalecer y organizar la futura colonia "germana" del Chubut a la que, significativamente, bautizó Friedland en memoria de su ciudad natal. Desde su retorno a la capital

40. La Nación (Buenos Aires) 14 de diciembre de 1905.

41. Horacio Ibarra, Proyectos económicos, políticos y culturales para la Patagonia desde el siglo XIX hasta el presente (Rawson: Secretaría de Cultura de la Provincia del Chubut, 2009).

42. Argentinisches Tageblatt (Buenos Aires) 13 de enero de 1905: 1. En Alemania se ocuparía de dar visibilidad a la nueva empresa de colonización junto a Jannasch y Hauthal, el primero de los cuales se encontraba ya en plena tarea. Efectivamente, el 17 de marzo de 1905 un numeroso público se había dado cita en el auditorio del Museo de Etnología de Berlín para escuchar la conferencia doble organizada por la ZVfHG en la que su presidente y Carlos A. Altgelt disertaron sobre el sur de Brasil y sobre "El Delta del Paraná”, respectivamente. Argentinisches Tageblatt (Buenos Aires) 5 de abril de 1905: 1. El padre de Carlos, de nombre Adam Altgelt,"uno de los alemanes más antiguos y de más largo afincamiento de Buenos Aires, la cabeza de una familia numerosa y de gran prestigio", murió en Argentina pocas semanas después a la edad de 80 años. Argentinisches Tageblatt (Buenos Aires) 4 de mayo de 1905: 1. Había sido el fundador de la firma Ferber, Altgelt \& Co., de la que surgiría la empresa Ferber, Hühn \& Co. y más tarde la Casa Tornquist \& Co., director del Banco Belga-Alemán del Río de la Plata en Montevideo y Buenos Aires y presidente honorario de la Asociación de Guerreros Alemanes de Buenos Aires. Fue uno de los pioneros de la colonización en el Delta, en cuya huella su hijo Carlos continuó trabajando, por ejemplo, siendo miembro fundador de la VzSgE como ya hemos apuntado. Por su parte, Rudolf Hauthal se sumaría recién a fines de 1905 dado que había recibido y aceptado la invitación de la Universidad de Hildesheim para hacerse cargo del prestigioso Museo Roemer, por lo que abandonó definitivamente el país y sus responsabilidades como naturalista del Museo de La Plata. Argentinisches Tageblatt (Buenos Aires) 9 de mayo de 1905: 1. 
el 18 de junio y hasta su partida, sus actividades se desplegaron en tres áreas fundamentales: publicidad y propaganda, gestiones ante el gobierno argentino y administración de la concesión.

En primer lugar, preparó de inmediato un informe de la concesión ideado para ser distribuido entre un público reducido compuesto por colonos, capitalistas y emprendedores del país; de allí que no se consiguiera en librerías, sino que solo estuviera "dirigido a interesados que quieran ocuparse de aquella importante cuestión colonizadora". Este exhaustivo estudio de una treintena de páginas, firmado en "Buenos Aires, junio de 1905" y titulado La región del Río Pico en el territorio nacional del Chubut (Argentina), ${ }^{43}$ fue publicado originalmente como panfleto en tamaño octavo, quizás asistido técnicamente por alguno de los diarios que frecuentó dado que en sus páginas no se indica ninguna editorial a cargo de la impresión. Si prescindimos de la conferencia de 1904, por haber sido publicada a demanda tanto del Deutsche La Plata Zeitung como del Argentinisches Tageblatt, este fue el primer texto impreso sobre sus experiencias de viaje en Suramérica y el único editado en el continente. Theodor Alemann, listado como uno de los futuros miembros de esa colonia, efectuó una breve reseña del texto en el Argentinisches Tageblatt y solicitó a Vallentin dar a conocer su contenido a un círculo más amplio, razón por la cual el folleto se publicó por entregas en el suplemento cultural y de divulgación científica del periódico. ${ }^{44}$

Por otro lado, los preparativos para la fundación de la sociedad DGwUA continuaron durante la ausencia de Vallentin bajo la dirección de una comisión preparatoria. En reunión del 27 de marzo se decidió por unanimidad asignar el dinero recaudado a una serie de importantes instituciones alemanas, entre las que no estaban ni la Asociación Escolar Alemana de Buenos Aires ni la VzFgE. En consecuencia, los hermanos Alemann retiraron su apoyo a la iniciativa y expresaron el deseo de fundar en el futuro una asociación sobre bases más amplias que este intento "tan dominado por el espíritu de la exclusividad". ${ }^{45}$ Este distanciamiento no supuso una ruptura definitiva. Tanto es así que Theodor publicó meses más tarde un elogioso artículo en favor de la formación de la nueva colonia, en el que situaba este proyecto en una perspectiva de larga duración que incluía sus propios llamados de atención sobre la región patagónica y consideraba que el intento de poblarla con población germana se emprendía ahora de manera definitiva. ${ }^{46}$

43. Wilhelm Vallentin, Das Gebiet am Pico-Fluss im National-Territorium Chubut (Argentinien) (Buenos Aires: [s.e.], [1905]).

44. La primera cita está contenida en la reseña aparecida en Argentinisches Tageblatt (Buenos Aires) 22 de julio de 1905: 1.Véase el suplemento Hüben und Drüben (Buenos Aires) 29 de julio de 1905; Hüben und Drüben (Buenos Aires) 5 de agosto de 1905; Hüben und Drüben (Buenos Aires) 12 de agosto de 1905. Sobre las características de este escrito y el lugar que ocupó en su obra general véase Gastón Olivera, "El 'Informe Vallentin' (1905): pieza clave de un corpus global”, Revista Electrónica de Fuentes y Archivos (REFA) 8.8 (2017): 175-198.

45. Argentinisches Tageblatt (Buenos Aires) 29 de marzo de 1905: 1. Traducción del autor.

46. "Ein deutsches Kolonisationsunternehmen in Patagonien", Argentinisches Tageblatt (Buenos Aires) 28 de julio de 1905: 1. 
En segundo lugar, el diálogo con el gobierno por la gestión de la concesión comenzó a mostrar algunas fisuras ligadas al origen de los futuros colonos (si se le iba a permitir o no a la colonia incluir a "germanos" residentes en el país) y al momento de efectuar la mensura (si se realizaría antes o después de la llegada de los colonos). Para resolver estas diferencias se sucedieron entre julio y agosto una serie de audiencias con el ministro Torino que dejaron en Vallentin las peores impresiones sobre este funcionario. ${ }^{47}$ Ante estas contrariedades y el surgimiento de algunos conflictos e intrigas al interior de la propia colectividad, otorgó poder general notarial a Adalberto Schmied, sito en Buenos Aires, quien respondería por cualquier trámite en relación a la concesión o a su poblamiento; además, lo hizo publicar en forma de "edicto" en los dos principales periódicos de habla alemana. De esta forma, intentó garantizar que durante su alejamiento del país la administración de la concesión permaneciera bajo su estricto control. ${ }^{48}$

En tercer lugar, el recorrido por Chubut había dejado en claro que las dificultades para acceder a la zona precordillerana podían comprometer la viabilidad de la colonia. Ante la inexistencia de trenes o de transporte fluvial y tampoco contar con alternativas a mediano plazo a las maltrechas huellas de carro, Vallentin y Schmied concibieron la idea de establecer una vía de comunicación rápida por medio de un servicio regular de automóviles para personas y tráfico de mercancías, el cual conectaría las poblaciones del oeste y centro con los puertos, mercados y con la población de la costa atlántica. ${ }^{49}$ Todos estos largos y costosos preparativos debían estar listos antes de fin del año 1905 “de manera tal que los colonos germanos obtengan o tomen en posesión sus nuevos hogares en aquella maravillosa, saludable y fértil zona". El decreto de reserva indicaba que los colonos debían estar establecidos a más tardar en enero de 1906.

Las observaciones y los encuentros que mantuvo en Chubut seguramente le hicieron tomar consciencia de la diversidad de intereses en juego, lo que le mostró lo imperioso de estrechar vínculos con los sectores locales que conocieran la dinámica territoriana y fueran afines a una eventual colonia germana. Se comprende entonces el acercamiento de Vallentin a la misión salesiana, a pesar de su procedencia de una familia y una región protestante de Alemania y sin tener la religión un peso importante en sus alocuciones y escritos. En Buenos Aires visitó al padre Lino Delvalle Carbajal en la escuela salesiana de Almagro y "salió de ella completamente

47. Vallentin, Ein Unerschlossenes 69.

48. No sabemos cómo ni cuándo conoció a su apoderado y son insuficientes los datos que hoy tenemos sobre él, incluso si existía un parentesco con Federico Schmied (ver nota al pie 38). El edicto se mantuvo publicado en el Argentinisches Tageblatt desde fines de julio y hasta su partida, desde el número 4881 del 24 de julio al número 4890 del 4 de agosto inclusive, y en el Deutsche La Plata Zeitung desde 5 de agosto (número 181).

49. Argentinisches Tageblatt (Buenos Aires) 28 de julio de 1905: 1. Traducción del autor. Este enfoque del problema parece confirmar que se privilegiaba el perfil atlántico de la colonia antes que la posibilidad de estrechar vínculos transfronterizos con las colonias alemanas de Chile. Los automóviles finalmente llegaron en octubre de 1905 y fueron los primeros en la historia del Chubut. 
entusiasmado". Los propios salesianos confirmarán meses más tarde esta posibilidad de colaboración: "[1] os colonos que el Dr.Vallentin piensa traer son del Sur de Alemania, y como pertenecen á la Religion católica, el mismo Sr.Vallentín piensa solicitar la cooperación de la Congregación Salesiana para el servicio religioso y escuelas". ${ }^{0}$

Según se desprende de la cálida salutación que el Argentinisches Tageblatt le brindó el día anterior a su partida, su voluntad era retornar al país a la brevedad: "[c]on el vapor 'Helgoland' de la línea Lloyd nos deja hoy para hacer una corta estancia en la vieja patria el señor Dr. W.Vallentin. Le deseamos un feliz viaje y el mayor éxito en su misión". Sin embargo, este vapor de la línea alemana Norddeutscher Lloyd zarpó rumbo a Bremen recién en la mañana del 8 de agosto. Gracias a ello sabemos que, para sorpresa de Vallentin, el propio presidente de la república Manuel Quintana y el ministro del interior Rafael Castillo le hicieron llegar un conjunto de retratos con sus respectivas dedicatorias, ante lo cual quedó el viajero "encantado por esta distinción”. Tras dos años y medio de viaje de investigación por Suramérica regresó a Alemania para seguir trabajando en pro de sus proyectos. ${ }^{51}$

\section{Palabras finales}

La colonia Friedland, piedra de toque de un proyecto de colonización de más vasto alcance, fue concebida desde una perspectiva geopolítica racializada que juzgaba a la gestión de las corrientes de emigración como un instrumento clave para el fortalecimiento de la propia nación en el escenario mundial abierto por el nuevo siglo. Para explicar su formulación, sin embargo, no alcanza con exponer - como hemos hecho en otros trabajos - la genealogía académica y profesional de su promotor; ni es suficiente con discutir la agenda política colonial de los círculos militares y universitarios metropolitanos que este supo frecuentar; tampoco basta con identificar las líneas de publicación de las editoriales con las que se vinculó, o con poner al descubierto la trama de intereses económicos de la que provenía. Es preciso tener en cuenta el impacto que la experiencia en el territorio pudo tener sobre sus planes, visión del mundo y escritura; debido a esto hemos considerado relevante posar nuestra mirada más detenidamente sobre su breve paso por Argentina.

El seguimiento de sus acciones arroja un primer rasgo distintivo: no se trató solamente de "un" viaje a ese país, sino, más bien, de la parte de un recorrido que se inscribía en un interés político-económico (wirtschaftspolitisch) más amplio por las repúblicas suramericanas. La reconstrucción de su itinerario deja en claro, además, que su estadía se repartió en varios tramos de corta y mediana duración y que permaneció su ruta abierta a las circunstancias y a las sugerencias que iba recibiendo; una característica saliente durante toda su estadía en el continente.

50. Cruz del Sur (Rawson) 3 de septiembre de 1905: 143 y Cruz del Sur (Rawson) 5 de noviembre de 1905: 180, respectivamente.

51. Argentinisches Tageblatt (Buenos Aires) 7 de agosto de 1905: 1 y Argentinisches Tageblatt (Buenos Aires) 8 de agosto de 1905, respectivamente. Traducción del autor. 
En virtud de ello se comprende mejor el hecho de que solicitara una reserva de tierras sin haber conocido aún los territorios del sur. En su conferencia de 1904 solo había proyectado la posibilidad de conformar una asociación de colonización, pero nada insinuaba sobre Patagonia ni mucho menos sobre una concesión. Por cierto, cabe preguntarse ¿cómo consiguió tal otorgamiento en el plazo de algunos meses, si arribó al país como un total desconocido? ¿Cómo supo de la disponibilidad de esas tierras? O, más llanamente, ¿por qué Río Pico? ¿De dónde obtuvo los nombres de potenciales colonos que nutrieron la propuesta? ¿Cómo pudo aventurar el compromiso de establecerlos en el plazo de catorce meses sin conocer aún la región, como sí conocía ya otras? Concluimos que el proyecto de fundar una colonia "germana" en Chubut — si bien basado en las ideas en las que se había formado profesionalmente, las cuales maduró durante su experiencia colonialista y que ahora guiaban su evaluación del continente suramericano- se gestó durante su estadía en este país.

En buena medida germinó a partir del conocimiento que algunos miembros de la élite de habla alemana local tenían de esa región tras haberla recorrido como periodistas-viajeros (los Alemann), como científicos en funciones para el estado argentino (Hauthal y sus colegas del Museo de la Plata) o como emprendedores y pobladores particulares (Hahn, Schmied, entre otros). Fue estimulado a partir del conocimiento que este heterogéneo grupo había conseguido en anteriores experiencias de colonización en distintos puntos del país (Stroeder, Keller, Matschnig), lo que les permitió blandir un programa propio de fomento de la inmigración germanoparlante con el que Vallentin entró en contacto, pero que finalmente no hizo suyo. La iniciativa fue apuntalada, además, por el capital social que este grupo dirigente había adquirido desde las postrimerías del siglo XIX, lo que incrementó sensiblemente sus contactos con la propia élite argentina.Y quizás, principalmente, coincidió con la coyuntura abierta por los "Pactos de Mayo" de 1902 que resolvieron el litigio limítrofe con el vecino país e hicieron de esa zona un lugar propicio desde el punto de vista gubernamental para ese tipo de iniciativas.

Sin ese terreno fértil favorecido por aquellas élites y sus redes sociales, científicas y políticas, su experiencia hubiera sido otra. Vallentin forjó su identidad, perspectivas y proyectos al calor de las situaciones que vivenció en los diversos escenarios que recorrió y, guiado por el sentido de la oportunidad, estas circunstancias le llevaron del diagnóstico a la acción, incluso a expensas del plan original de viaje que incluía una visita más exhaustiva de Chile y de Perú — destino este último que finalmente nunca conoció- $-{ }^{52} \mathrm{Al}$ comprender que no actuó en soledad, sino que lo hizo al interior de una trama socioeconómica y política preexistente, podemos divisar la complejidad de su agencia histórica más allá de las visiones generalistas o romantizadas que han dominado el abordaje de esta "curiosa figura".

Así, la "trayectoria global" de Wilhelm Vallentin al ser considerada en una circunstancia histórica circunscrita revela cánones de pensamiento y patrones de acción disponibles tanto en la sociedad alemana como en la argentina de la época. De esta

52. Argentinisches Tageblatt (Buenos Aires) 7 de abril de 1904: 1. Traducción del autor. 
forma, pone de manifiesto que "lo global no es una esfera distinta, externa a los casos locales/nacionales", sino más bien "una escala a la que cabe hacer referencia incluso cuando observamos vidas individuales y espacios pequeños". ${ }^{53}$ Antes que ser una estructura reificada, estas escalas permiten al historiador evaluar con cierta plausibilidad cómo las interacciones y redes incidieron, qué alcances tuvieron y qué agencias o estructuras local-regionales estaban en acción, así como dónde y por qué las conexiones hallaron sus límites.

Porque si los vínculos encontrados o construidos in situ por Vallentin ofrecían un gran potencial, también podían mutar fácilmente en una hipoteca difícil de sostener, si su proyecto dejaba de coincidir con las aspiraciones de los actores locales, o si no tomaba suficientemente en cuenta los intereses en pugna, en particular en el propio territorio del Chubut. En efecto, durante su estadía en Alemania la administración de la futura colonia, a cargo de Adalberto Schmied, pese a algunos avances iniciales, comenzó a experimentar problemas que se agudizaron con el envío por parte del gobierno argentino en marzo de 1907 de una inspección de rutina. La División de Tierras y Colonias fue informada que los pobladores que la ley obligaba a instalar en el plazo estipulado no se encontraban residiendo en el lugar. El inspector Javier Marazzo utilizó el folleto propagandístico elaborado por Vallentin para cotejar sobre el terreno el grado de avance de la colonia, e incluso ilustró el expediente que inició con las fotografias tomadas por el viajero, las cuales recortó prolijamente de la publicación. Para mayor ironía, el Informe Marazzo presentado el 25 de junio de 1907 fue el acto administrativo que desencadenó el fin del proyecto de colonia "germana" en Chubut, pues revocó la concesión el 20 de agosto de ese mismo año. ${ }^{54}$ Pero no será este el lugar en el que nos ocupemos de la deriva de la colonia, o de lo que ocurrió tras su partida de Argentina.

\section{Fuentes}

\section{Manuscritas}

Archivo Histórico de la Provincia del Chubut, Rawson, Argentina (AHPCh) Fondo General

Instituto Autárquico de Colonización y Fomento Rural, Rawson, Argentina (IAC)

\section{Impresas}

Alemann, Moritz. Am Rio Negro. Ein Zukunftsgebiet germanischer Niederlassung: drei Reisen nach dem argentinischen Rio Negro-Territorium. Berlin: Dietrich Reimer, 1907.

53. Conrad 125.

54. Dirección General de Tierras y Colonias, Inspección General de Territorios Nacionales, 1907. IAC, Rawson, leg. 83, ff. 138-141. 
Matschnig, Alwin. Argentinien als Ziel für germanische Auswanderung. Buenos Aires: H. Herpig, 1906.

Vallentin, Wallentin. Chubut: Im Sattel durch Kordillere und Pampa Mittel-Patagoniens (Argentinien). Berlin: Hermann Paetel, 1906.

. Das Gebiet am Pico-Fluss im National-Territorium Chubut (Argentinien). Buenos Aires: [s.e.], [1905].

. Ein Unerschlossenes Kulturland. Nëuquén und Rio Negro (Argentinien). Berlin: Hermann Paetel, 1907.

. Kolonialpolitische Studien mit besonderer Berücksichtigung Argentiniens. Buenos Aires: Separatabdruck aus der Deutschen La Plata Zeitung und La Plata Post, 1904.

\section{Periódicos y revistas}

Argentinisches Wochenblatt (Buenos Aires) 1902-1907.

Argentinisches Tageblatt (Buenos Aires) 1902-1907.

Berliner Tageblatt und Handels-Zeitung (Berlin) 1902.

Caras y Caretas (Buenos Aires) 1903.

Cruz del Sur (Rawson) 1905.

Deutsche La Plata Zeitung (Buenos Aires) 1905.

Deutsche Rundschau für Geographie und Statistik (Wien-Pest-Leipzig) 1900.

El Pueblo (Trelew) 1919.

Hüben und Drüben (Buenos Aires) 1905.

La Nación (Buenos Aires) 1905.

Y Drafod (Trelew) 1904-1905.

\section{Bibliografía}

Barker, Chris. The SAGE Dictionary of Cultural Studies. London: SAGE Publications, 2004.

Braun Menéndez, Armando. "El aporte alemán al progreso de la Patagonia”. Revista Argentina Austral 33.348 (1961): 8-10.

Bryce, Benjamin. Ser de Buenos Aires. Alemanes, argentinos y el surgimiento de una sociedad plural 1880-1930. Buenos Aires: Editorial Biblos, 2019.

Conrad, Sebastian. Historia global. Una nueva visión para el mundo actual. Barcelona: Crítica, 2017.

Hausberger, Bernd. Ed. Globale Lebensläufe. Menschen als Akteure des weltgeschichtlichen Geschehen. Wien: Mandelbaum-Verlag, 2006.

Hoffmann, Katrin. “¿Construyendo una 'comunidad’? Theodor Alemann y Hermann Tjarks como voceros de la prensa germanoparlante en Buenos Aires, 1914-1918”. Iberoamericana 9.33 (2009): 121-137.

Ibarra, Horacio. Proyectos económicos, políticos y culturales para la Patagonia desde el siglo XIX hasta el presente. Rawson: Secretaría de Cultura de la Provincia del Chubut, 2009. 
Lütge, Wilhelm y otros. Los alemanes en la Argentina. 500 años de historia. Buenos Aires: Editorial Biblos, 2017.

Olivera, Gastón. Del desamparo al imperio. Wilhelm Vallentin y el proyecto de colonizacion del Chubut bajo el signo del Kaiserreich, 1890-1914. Buenos Aires: Prometeo Libros, 2015.

. "El 'Informe Vallentin' (1905): pieza clave de un corpus global”. Revista Electrónica de Fuentes y Archivos (REFA) 8.8 (2017): 175-198.

Pons, Anaclet. "De los detalles al todo: historia cultural y biografias globales". História da Historiografia 12 (2013): 156-175.

Riccardi, Alberto C. "El Museo de La Plata en el avance del conocimiento geológico a fines del siglo XIX”. Serie Correlación Geológica 24 (2008): 109-126.

Saint Sauveur-Henn, Anne. Un siècle d'emigration allemande vers l'argentine, 1853-1945. Colonia: Böhlau, 1995. 